\title{
Outbreak of systemic Candida albicans in intensive care unit caused by cross infection
}

\author{
J P BURNIE, F C ODDS W LEE, C WEBSTER, J D WILLIAMS
}

\begin{abstract}
The first documented outbreak of systemic candidosis shown to be due to cross infection with a particular strain of Candida albicans is reported. Over nine months in an intensive care unit 13 patients developed definite and one probable systemic candidosis. Twenty five further patients had superficial candidal infections. The strain that caused the outbreak (serotype $A$, morphotype A1, biotype $0 /{ }_{1} 55 / 7$ ) was responsible for all the cases of systemic candidosis acquired in the intensive care unit, $11(44 \%)$ of the superficial candidal infections in the unit, and $17 \%$ of candidal infections outside the unit but in the same hospital. The strain was also isolated from oral swabs taken from four nurses working in the unit and the hands of one of these nurses. Two out of 17 nurses were shown to have acquired the strain on their hands when examined immediately after nursing systemically infected patients. No environmental source could be identified. The strain also showed enhanced survival in handwashing experiments and was relatively resistant to Hibiscrub.

Management of patients with systemic candidosis might include measures to prevent cross infection and handwashing with disinfectants that are active against candida.
\end{abstract}

\section{Introduction}

The incidence of systemic candidosis is increasing, and this trend is likely to continue as the population of susceptible patients increases. ${ }^{1}$ Mortality is high $(75 \%)$ despite treatment with amphotericin B, which is nephrotoxic. ${ }^{2}$ Chemoprophylaxis with oral antifungal agents is therefore being used increasingly in patients at high risk of infection, as the gastrointestinal tract is regarded as the major source of invasive candidosis. ${ }^{3}$ High dosages of oral nystatin, amphotericin B, or ketoconazole reduce colonisation and may decrease the incidence of invasive candidosis in neutropenic patients. No form of chemoprophylaxis, however, is completely satisfactory. ${ }^{4-6}$

The development of invasive candidosis is usually attributed to autoinfection by yeasts colonising the patient's bowel or intravenous catheters. ${ }^{7-9} \mathrm{~A}$ recent outbreak of systemic infection with Candida parapsilosis, however, was due to exogenous infection from contaminated intravenous feeds. ${ }^{10}$ We describe the first reported outbreak of systemic infections caused by $C$ albicans. Clustering of such cases has been observed previously in heroin addicts. ${ }^{11}$

\section{Patients and methods}

Thirteen patients in the intensive care unit at the London Hospital

Department of Medical Microbiology, London Hospital, London E1 J P B URNIE, MB, MRCP, lecturer

W LEE, BSC, research assistant

J D WILLIAMS, MD, FRCPATH, professor of microbiology

Department of Medical Misrobiology, University of Leicester, Leicester

F C ODDS, BSC, PHD, senior lecturer

C WEBSTER, BSC, research assistant

Correspondence to: Dr J P Burnie. acquired systemic candidosis during July 1983 to March 1984 Diagnosis was made on the basis of one or more of the following criteria: cultural and histological evidence from deep organ biopsy at necropsy (seven patients) or during life (two patients); and two blood cultures that yielded positive results taken from two different intravenous lines at least 24 hours apart (10 patients). In six cases results of both necropsy and blood cultures were positive. One further patient was considered likely to have had systemic candidosis as $C$ albicans was isolated from a pleural aspirate and his serum gave positive titres in a serodiagnostic test for candidal antigen (JPB, unpublished results).

Twenty five further patients from the intensive care unit had superficial candidal infections. Two patients were transferred to the unit having acquired systemic candidosis while at other hospitals. Most patients in the unit had had operations. Seventy two patients outside the unit with superficial candidal infections were also studied.

Isolates of yeasts were obtained from postmortem material, blood cultures, urine, and sputum or wounds or both from patients in the intensive care unit. During the last four months of the study formal screening for oral and perineal carriage of yeasts was performed each week on 70 patients in the unit. Sixty five nursing staff were screened for oral and perineal candida and their hands examined by an enrichment method modified from that of Casewell and Phillips. ${ }^{12}$ In addition, the enrichment method was used to examine the hands of 17 nurses before and after they nursed systemically infected patients to observe the ease with which candida could be transferred from patient to nurse. Extensive cultures were taken from fomites in the unit, and agar plates were left open overnight to sample the air.

Yeast isolates were identified, and $C$ albicans was biotyped by nine biochemical tests on agar plates according to the method of Odds and Abbott. ${ }^{13}$ Results of the nine tests were coded into specific three digit octal numbers. ${ }^{14}$ Additional information about phenotypes was obtained by examining morphology on malt extract agar ${ }^{15}$ and serotyping with cross absorbed rabbit hyperimmune serum raised against $C$ albicans NCTC 3153 (serotype A). ${ }^{16}$

Survival of $C$ albicans on hands and blocks of Formica was examined as described for klebsiella by Casewell and Desai. ${ }^{17} \mathrm{~A}$ block of Formica or a fingertip was inoculated with $10^{4}$ yeasts and counts performed over 90 minutes. The effect of washing the finger with $5 \mathrm{ml} \mathrm{Hibiscrub}$ (Imperial Chemical Industries, United Kingdom) after 60 minutes was also studied. The survival of the strain that caused the outbreak was compared with that of a serotype $B$ blood culture isolate from one patient (case 9) and two control strains (NCTC 3153 and NCTC 3156). Each experiment was performed in triplicate, and the handwashing experiments were carried out on the same three volunteers.

\section{Results}

Isolates were available from 12 of the 13 with proved and the patient with probable systemic candidosis acquired in the intensive care unit and from both patients (cases 9 and 13) transferred from other hospitals (table). Each isolate of $C$ albicans had the following phenotype: serotype $A$, morphotype $A 1$, variable tolerance to $\mathrm{pH} 1 \cdot 4$, no proteinase secretion, no resistance to flucytosine, no tolerance to salt, variable resistance to boric acid, resistance to safranine, assimilation of urea and citrate but not sorbose. The results from the nine biochemical tests were subdivided into three groups so that each number in the biotype referred to a summary of three tests. The outbreak strain was defined as serotype $A$, morphotype Al, biotype $0 / 155 / 2$, the variability in the biotype code being due to replicate variation in tolerance to $\mathrm{pH} 1.4$ and resistance to boric acid.

Five of the patients were transiently colonised by species other than $C$ albicans or $C$ albicans with a different phenotype, but these invariably came from more superficial sources (sputum or urine) than the outbreak strain (blood cultures, biopsy, or postmortem material). The two patients transferred to the intensive care unit having acquired systemic candida elsewhere were infected with a different phenotype from the outbreak strain. One patient (case 15), whose blood culture isolates changed from the phenotype of the outbreak 
strain to a phenotype that was resistant to flucytosine (475), was treated with this drug for his candidal infection; the change in phenotype presumably resulted from the selective pressure of the drug treatment. Only two patients survived (cases 11 and 13).

Of the 25 patients in the intensive care unit with superficial candidal infections, 11 carried the outbreak strain. Of these 11 patients, eight carried the organism in their sputum, two had colonised wounds, and one had a urinary tract infection. The urinary tract infection was successfully treated with oral flucytosine. The prevalence of the outbreak strain $\left(44^{\circ}\right)$ was similar to that found in the oral and perineal screening survey, where the outbreak strain was found in 10 of 28 patients $\left(36^{\circ}\right)$ ) who carried yeasts in the mouth or perineum (out of a total of 70 patients who passed through the ward during the survey). Of 72 patients in the hospital but not in the intensive care unit, $12\left(17^{\circ} \mathrm{o}\right)$ were found to harbour the outbreak strain of $C$ albicans. These differences in prevalence were significant by $\chi^{2}$ analysis. The prevalence among patients with superficial infection in the unit was significantly greater $(p<0.01)$ than the prevalence outside the unit.

About $10 \%$ of the staff carried yeasts on their hands, but in only

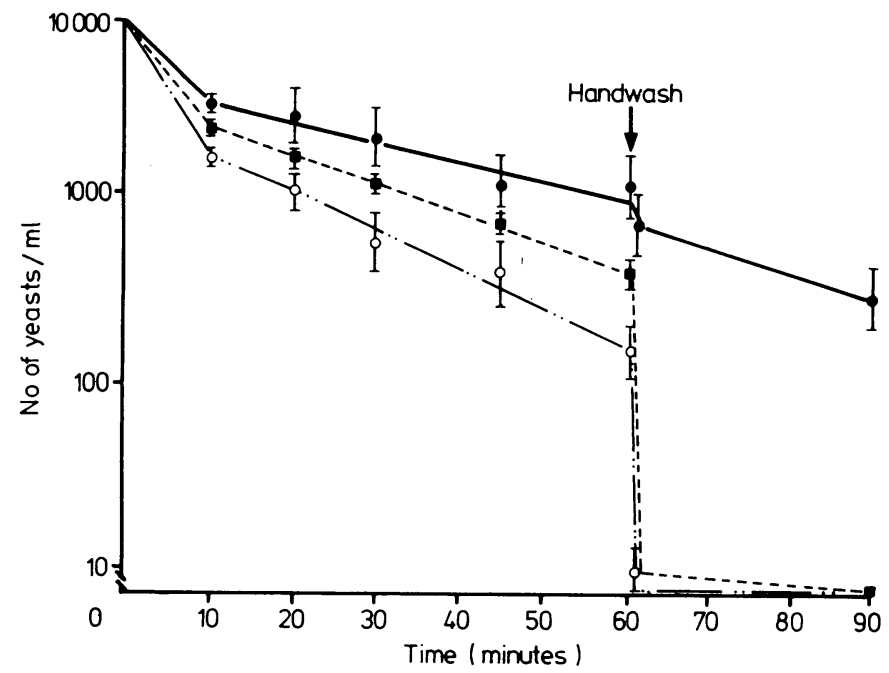

Survival of Candida albicans on hands before and after washing with $5 \mathrm{ml}$ Hibiscrub. - - Strain that caused the outbreak; $-.-0:=$ Serotype B blood culture isolate; $O-O=$ Control strain NCTC 3156. NCTC 3153 produced a curve similar to the serotype B blood culture isolate. Bars represent $\mathrm{SD}$, based on experiments done in triplicate on three volunteers. two cases were these $C$ albicans. One was type 457/A6/B, and the other, from a nurse looking after one patient (case 11), was the outbreak strain. Two out of 17 nurses were found to have acquired the outbreak strain when their hands were examined by the enrichment method before and after they nursed patients with systemic infections. A third nurse had symptomatic vaginal candida due to this strain. Among the 65 staff sampled four were oral carriers of the outbreak strain. One nurse carried type $457 / \mathrm{A6} / \mathrm{B}$ in the mouth and perineum.

The agar plates left open overnight and samples of fomites from the unit yielded many yeast isolates, but only one was $C$ albicans, type $117 \mathrm{~A} 1 \mathrm{~B}$, and this was obtained from the dirty linen of a patient (case 9) who carried this strain. No obvious correlation was found between the particular bed occupied and colonisation. All beds in the unit had from three to seven patients admitted to them.

The handwashing experiments (figure) showed that the outbreak strain survived better over 60 minutes than other isolates and the control strains. Washing with Hibiscrub resulted in the disappearance of the control strain NCTC 3156. There was an appreciable reduction in the amounts of both the serotype B blood culture isolate and the other control strain NCTC 3153. After a further 30 minutes the serotype $B$ blood culture isolate was undetectable but the control strain still produced just detectable counts. Growth of the outbreak strain was only marginally reduced by washing with Hibiscrub and was still present in appreciable amounts $(>100$ organisms $/ \mathrm{ml}$ ) after a further 30 minutes. The results of survival on blocks of Formica for 90 minutes showed no significant difference between the four strains. With an inoculum of $10^{4}$ cells a reduction of about one logarithm was seen after 15 minutes, and about two logarithms after 90 minutes.

\section{Discussion}

Epidemics of candidal infections are unusual. Two outbreaks of cutaneous candidal infection have been documented, ${ }^{18}{ }^{19}$ and in both of these the source was shown to be a contaminated fomite. Recently, an outbreak of $C$ parapsilosis septicaemia was reported, and this was associated with contaminated intravenous feeds. ${ }^{10}$ Ours is the first documented outbreak of systemic infections caused by $C$ albicans. The strain responsible was isolated more often from the intensive care unit than elsewhere in the hospital. Colonisation of sputum, gut, or urinary tract seemed to precede systemic infection in this outbreak. In only one patient (case 7) was there colonisation of intravenous lines before systemic infection. This outbreak therefore bears no resemblance to that described by Solomon et al, in which intravenous feeding was incriminated. ${ }^{10}$

The 294 patients admitted to the intensive care unit during

Details of 15 patients with definite and one with probable (case 14) systemic candidal infection in intensive care unit

\begin{tabular}{|c|c|c|c|c|c|}
\hline $\begin{array}{l}\text { Case } \\
\text { No }\end{array}$ & $\begin{array}{l}\text { Age (years) } \\
\text { and sex }\end{array}$ & $\begin{array}{l}\text { Length of stay } \\
\text { in days* }\end{array}$ & Underlying diagnosis & Source of isolate & $\begin{array}{c}\text { Phenotype } \\
\text { (biotype, morphotype, serotype) }\end{array}$ \\
\hline 1 & $42 \mathrm{~F}$ & $8(5)$ & Drug addiction & Blood culture & 055, A1, A† \\
\hline 2 & $64 \mathrm{M}$ & $33(10)$ & After cholecystectomy & Blood culture & $055, \mathrm{Al}, \mathrm{A} \dagger$ \\
\hline 3 & $56 \mathrm{M}$ & $43(10)$ & Left ventricular failure & Blood culture & 157, A1, A $\dagger$ \\
\hline 4 & $72 \mathrm{M}$ & $22(7)$ & After cholecystectomy & Laparotomy & Not available \\
\hline 5 & $77 \mathrm{~F}$ & $10(5)$ & After arteriovascular operation & Blood culture & $0,157, \mathrm{Al}, \mathrm{A}+$ \\
\hline 6 & $64 \mathrm{~F}$ & $15(10)$ & After bronchoscopy & $\{$ Sputum, ante mortem & $355, \mathrm{Al}, \mathrm{A}$ \\
\hline 7 & $57 \mathrm{M}$ & 13 (3) & Staphylococcus epidermidis endocarditis & $\begin{array}{l}\text { Lung, post mortem } \\
\text { Blood culture, heart valve, and meninges post mortem }\end{array}$ & $\begin{array}{l}\text { 057, Al, A } \\
\text { 057, Al, A } \dagger\end{array}$ \\
\hline 8 & $36 \mathrm{~F}$ & $21(15)$ & Systemic lupus erythematosus & $\left\{\begin{array}{l}\text { Urine } \\
\text { Blood culture }\end{array}\right.$ & 157, A1, At \\
\hline 9 & $65 \mathrm{M}$ & $11(-) \S$ & After gastrectomy & Sputum, post mortem & $117, \mathrm{~A} 1, \mathrm{~B}$ \\
\hline 10 & $21 \mathrm{~F}$ & $29(15)$ & Staphylococcus aureus septicaemia & $\left\{\begin{array}{l}\text { Sputum, urine } \\
\text { Blood culture, post mortem }\end{array}\right.$ & $\begin{array}{l}315, \mathrm{Al}, \mathrm{B} \\
\text { 055, Al, A+ }\end{array}$ \\
\hline 11 & $34 \mathrm{M}$ & $51(5)$ & Crohn's disease & $\left\{\begin{array}{l}\text { Wound, sputum } \\
\text { Urine } \\
\text { Laparotomy }\end{array}\right.$ & $\begin{array}{l}\text { 055, A1, A† } \\
\text { 255, A1, A } \\
\text { Not available }\end{array}$ \\
\hline 12 & $72 \mathrm{M}$ & $11(6)$ & After aortoiliac bypass operation & $\left\{\begin{array}{l}\text { Sputum } \\
\text { Blood culture }\end{array}\right.$ & $\begin{array}{l}\text { Ctropicalis } \\
157, \mathrm{Al}^{+},\end{array}$ \\
\hline 13 & $34 \mathrm{~F}$ & $30(1) \S$ & Carcinoma of cervix & Wound, blood culture & $157, \mathrm{Al}, \mathrm{B}$ \\
\hline 14 & $61 \mathrm{M}$ & $8(5)$ & Carcinoma of oesophagus & Pleural aspirate & 057, Al, At \\
\hline 15 & $49 \mathrm{M}$ & $13(5)$ & After oesophagogastrectomy & $\left\{\begin{array}{l}\text { Sputum, blood culture } \\
\text { Blood culture }\end{array}\right.$ & $\begin{array}{l}\text { 157, A1, A† } \\
\text { 475, A1, A }\end{array}$ \\
\hline 16 & $63 M$ & $11(6)$ & After duodenal ulcer surgery & $\left\{\begin{array}{l}\text { Sputum } \\
\text { Blood culture }\end{array}\right.$ & $\begin{array}{l}\text { Ctropicalis } \\
157, \mathrm{~A} 1, \mathrm{~A}+\end{array}$ \\
\hline
\end{tabular}

- Number in brackets is number of days that elapsed before first isolation of Candida from any site. 
the study were grouped according to their length of stay in the unit. The prevalence of the outbreak strain among patients who spent less than three days in the unit was $0.85 \%(2 / 235$ patients), compared with 54\% (32/59) among those who stayed in the unit for more than three days. Among this second group, the 27 patients who never carried the outbreak strain spent an average of 8.6 days in the unit (total 233 days) whereas the 32 patients who did acquire the outbreak strain spent an average of 21 days in the unit (total 673 days). Thus there was a higher risk of colonisation by the outbreak strain for patients who remained in the unit for a long time. The average time between admission to the unit and colonisation with the outbreak strain was 6.6 days. This was consistent with a model of superinfection with an exogenous candidal strain. Four of the patients who subsequently died from infection with the outbreak strain were initially colonised by a different candidal phenotype. In two cases this was $C$ tropicalis. These patients did not develop systemic disease from their original endogenous yeast but became superinfected by the endemic outbreak strain, which then disseminated.

The outbreak was due to a particular strain of $C$ albicans (serotype A, morphotype A1, biotype $0 / 155 / 7$ ). This strain survived better on nurses' hands than control strains of $C$ albicans and was considerably more resistant to washing with Hibiscrub, the disinfectant mainly in use at the time of the study. The lack of an environmental source agrees with earlier work $^{20}{ }^{21}$ and accords with the observation that the outbreak strain did not survive better on blocks of formica than the control strains.

Of the 65 staff examined, four were oral carriers of the outbreak strain and one carried this strain on her hands. While nursing patients with systemic infections two out of 17 nurses acquired the outbreak strain. One nurse developed clinical vaginal candidosis 48 hours after nursing a patient (case 15). She had no history of the disease, and the isolate was the same as the outbreak strain. The data suggest that the cycle of infection lies between patients and staff.

In conclusion, we found that one particular strain of $C$ albicans was capable of causing systemic candidosis as a result of cross infection between patients and staff. It not only caused invasive infections but showed a propensity to spread, possibly due to its relative resistance to washing with Hibiscrub. Previously, chemoprophylaxis has concentrated on eradicating endogenous yeast flora from the gastrointestinal tract. ${ }^{3}$ This should perhaps be combined with isolation of patients with systemic infections and heavy colonisation as well as handwashing with disinfectants that are active against candida.

We thank the consultants, medical staff, and nurses in the intensive care unit, London Hospital, for their help, Professor M W Casewell for valuable discussion, and Janssen Pharmaceutical for a grant supporting Mrs C Webster.

\section{References}

1 Fraser DW, Ward JI, Ajello L, Plikaytis BD. Aspergillosis and other systemic mycoses: the growing problem. $\mathcal{F} A M A 1979 ; 242: 1631-5$ . Opportunistic fungal infections in patients with neoplastic disease. Am $\mathcal{Y}$ Med $1984 ; 76: 458-63$. 1984;76:652-6. eunier-Carpentier F, Kiehn T, Armstrong D. Fungemia in the immunocompromised host. Changing patterns, antigenemia, high mortality. Am $\mathcal{J}$ Ezdinli E, O'Sullivan D, Wasser L, Kim U, Stutzman L. Oral amphotericin for candidosis in patients with hematologic neoplasms. An autopsy study. $\mathcal{J} A M A$ 1979;242:258-60.

6 Donnelly JP, Starke ID, Galton DAG, Catovsky D, Goldman JM, Darrell JH. Oral ketoconazole and amphotericin $B$ for the prevention of yeast colonization in patients with acute leukaemia. $\mathcal{F}$ Hosp Infect 1984;5:83-91

7 Evans EGV, Forster RA. Antibodies to Candida after operations on the heart J Med Microbiol 1976;9:303-8.

Krause W, Matheis $\mathbf{H}$, Wulf $\mathrm{K}$. Fungaemia and gunguria after oral administra-

9 Stone HH, Kolb LD, Currie CA, Geheber CE, Cuzzell JZ. Candida sepsis: pathogenesis and principles of treatment. Ann Surg 1974;179:697-711. bloodstream infections in patients receiving parenteral nutrition. $\mathcal{Z}$ Infect $D$ is 1984;149:98-103.

11 Drouet E, Dupont B. Laboratory and clinical assessment of ketoconazole in deep seated mycoses. Am $\mathcal{F}$ Med 1983;74:30-47.

12 Casewell MW, Phillips 1 . Hands as route of transmission for Klebsiella species. Br Med $\mathcal{F} 1977$;i : 1315-7.

13 Odds FC, Abbott AB. Modification and extension of tests for differentiation of Candida species and strains. Sabouraudia 1983;21:79-81.

14 Odds FC, Abbott AB. A simple system for the presumptive identification of Candida albicans and differentiation of strains within the species. Sabouraudic 1980;18:301-17.

5 Brown-Thomsen J. Variability in Candida albicans (Robin). Hereditas 1968; 60:355-98.

Hasenclever HF, Mitchell WO. Antigenic studies of Candida. I. Observation of two antigenic groups in Candida albicans. 7 Bacteriol $1961 ; 82: 570-3$.

17 Casewell MW, Desai N. Survival of multiply-resistant Klebsiella aerogenes and other Gram-negative bacilli on fingertips. $\mathcal{J}$ Hosp Infect 1983;4:350-60.

18 Cremer G, DeGroot WP. An epidemic of thrush in a premature nursery. Dermetologia 1967;135:107-14.

19 Malamatinis JE, Mattmiller ED, Westfall JN. Cutaneous moniliasis affecting varsity athletes. Fournal of the American College Health Association 1968;16: 294-5.

20 Clayton YM, Noble WC. Observations on the epidemiology of Candida albicans. I Clin Pathol 1966;19:76-8. Midgley G, Clayton YM. Distribution of dermatophytes and candida spores in
the environment. Br 7 Dermatol $1972 ; 86: 69-77$.

(Accepted 28 December 1984)

.

\section{SHORT REPORTS}

\section{Prolonged hypercalcaemia after industrial exposure to vitamin $\mathrm{D}_{3}$}

Hypercalcaemia due to vitamin D intoxication is usually the result of a prolonged oral intake or overdosage. Individual tolerance may vary and occasionally patients may be sensitive to low doses. We report a case in which brief exposure to a process manufacturing vitamin $\mathrm{D}_{3}$ (cholecalciferol) led to prolonged intoxication and hypercalcaemia.

\section{Case report}

A previously fit 32 year old laboratory technician presented on 21 April 1983 with a three week history of increasing polydipsia, anorexia, nausea, and general malaise. He had no medical history and was not taking any medication. He had helped in the crystallisation of vitamin $D_{3}$ for 32 days in 1981, 11 days in 1982, and 22 days in 1983. Symptoms had started two days after he had last begun working on the manufacture of vitamin $D_{3}$. There had been no other relevant exposure. A dust mask, laboratory coat, and gloves had been worn during all the procedures. Examination showed a fit, lean young man who had signs of mild dehydration. His blood pressure was $120 / 80 \mathrm{~mm} \mathrm{Hg}$ with no postural drop and he was clinically normal.
The initial serum calcium concentration was $3.5 \mathrm{mmol} / 1(14.0 \mathrm{mg} / 100 \mathrm{ml})$ (normal 2.2-2.7 mmol/l), phosphate $1.06 \mathrm{mmol} / 1(3.3 \mathrm{mg} / 100 \mathrm{ml}$ ) (normal $0.8-1.45 \mathrm{mmol} / \mathrm{l})$, alkaline phosphatase activity $154 \mathrm{U} / \mathrm{l}(8 \mathrm{KA}$ units $/ 100 \mathrm{ml})$ (normal $100 \mathrm{U} / \mathrm{l})$, and blood urea concentration $9 \cdot 1 \mathrm{mmol} / 1(55 \mathrm{mg} / 100 \mathrm{ml})$ (normal $2 \cdot 5-7.5 \mathrm{mmol} / \mathrm{l}$ ). Serum creatinine concentration was $170 \mu \mathrm{mol} / 1$ $(1.9 \mathrm{mg} / 100 \mathrm{ml})($ normal $30-170 \mu \mathrm{mol} / \mathrm{l})$. The chest radiograph was normal and abdominal radiography showed no evidence of nephrocalcinosis. The parathyroid hormone concentration was less than $0 \cdot 1 \mu \mathrm{g} / 1$ (normal less than $0 \cdot 1-0 \cdot 73$ ).

The patient was treated with intravenous saline, frusemide $40 \mathrm{mg}$ eight hourly, and hydrocortisone $200 \mathrm{mg}$ six hourly. His general condition improved and the calcium concentration dropped to $2.5 \mathrm{mmol} / 1(10.0 \mathrm{mg} /$ $100 \mathrm{ml}$ ) after 10 days of treatment. He was discharged and continued with prednisolone $30 \mathrm{mg}$ daily and a high fluid intake. He was readmitted a week later with a calcium concentration of $3.7 \mathrm{mmol} / 1(14.8 \mathrm{mg} / 100 \mathrm{ml})$, and despite adequate rehydration, low calcium diet, and steroids the calcium value remained high and widely fluctuant. He developed a gross Cushingoid appearance and hence the dose of hydrocortisone was gradually reduced over one week and replaced with dexamethasone, which has less tendency to cause fluid retention. Two weeks later he began cholestyramine $8 \mathrm{~g}$ twice daily, and over three weeks the calcium concentration fell, fluctuating between 2.5 and $2.85 \mathrm{mmol} / 1(10.0$ and $11.4 \mathrm{mg} / 100 \mathrm{ml})$. After eight weeks' treatment his calcium concentrations were normal and remained so with a normal diet and no treatment (figure). After the diagnosis there was no further exposure to vitamin $D_{3}$. The initial concentrations of 25-hydroxycholecalciferol one month after the exposure to vitamin $D_{3}$ were grossly 